NASA/TM-2005-214020

Hall Thruster Technology for NASA Science Missions

David Manzella

Glenn Research Center, Cleveland, Ohio

David Oh

Jet Propulsion Laboratory, Pasadena, California

Randall Aadland

Aerojet Corporation, Redmond, Washington 
Since its founding, NASA has been dedicated to the advancement of aeronautics and space science. The NASA Scientific and Technical Information (STI) Program Office plays a key part in helping NASA maintain this important role.

The NASA STI Program Office is operated by Langley Research Center, the Lead Center for NASA's scientific and technical information. The NASA STI Program Office provides access to the NASA STI Database, the largest collection of aeronautical and space science STI in the world. The Program Office is also NASA's institutional mechanism for disseminating the results of its research and development activities. These results are published by NASA in the NASA STI Report Series, which includes the following report types:

- $\quad$ TECHNICAL PUBLICATION. Reports of completed research or a major significant phase of research that present the results of NASA programs and include extensive data or theoretical analysis. Includes compilations of significant scientific and technical data and information deemed to be of continuing reference value. NASA's counterpart of peerreviewed formal professional papers but has less stringent limitations on manuscript length and extent of graphic presentations.

- TECHNICAL MEMORANDUM. Scientific and technical findings that are preliminary or of specialized interest, e.g., quick release reports, working papers, and bibliographies that contain minimal annotation. Does not contain extensive analysis.

- CONTRACTOR REPORT. Scientific and technical findings by NASA-sponsored contractors and grantees.
- CONFERENCE PUBLICATION. Collected papers from scientific and technical conferences, symposia, seminars, or other meetings sponsored or cosponsored by NASA.

- SPECIAL PUBLICATION. Scientific, technical, or historical information from NASA programs, projects, and missions, often concerned with subjects having substantial public interest.

- TECHNICAL TRANSLATION. Englishlanguage translations of foreign scientific and technical material pertinent to NASA's mission.

Specialized services that complement the STI Program Office's diverse offerings include creating custom thesauri, building customized databases, organizing and publishing research results ... even providing videos.

For more information about the NASA STI Program Office, see the following:

- Access the NASA STI Program Home Page at http://www.sti.nasa.gov

- E-mail your question via the Internet to help@sti.nasa.gov

- Fax your question to the NASA Access Help Desk at 301-621-0134

- Telephone the NASA Access Help Desk at 301-621-0390

- Write to:

NASA Access Help Desk

NASA Center for AeroSpace Information 7121 Standard Drive

Hanover, MD 21076 
NASA/TM-2005-214020

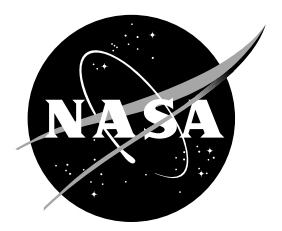

\section{Hall Thruster Technology for NASA Science Missions}

David Manzella

Glenn Research Center, Cleveland, Ohio

David Oh

Jet Propulsion Laboratory, Pasadena, California

Randall Aadland

Aerojet Corporation, Redmond, Washington

Prepared for the

41st Joint Propulsion Conference and Exhibit cosponsored by AIAA, ASME, SAE, and ASEE

Tucson, Arizona, July 10-13, 2005

National Aeronautics and

Space Administration

Glenn Research Center 


\section{Acknowledgments}

The authors would like to thank Carl Sauer for the analysis related to the asteroid sample return mission. A portion of the research described in this paper was carried out at the Jet Propulsion Laboratory, California Institute of Technology, under a contract with the National Aeronautics and Space Administration.

Available from

NASA Center for Aerospace Information 7121 Standard Drive

Hanover, MD 21076
National Technical Information Service 5285 Port Royal Road Springfield, VA 22100

Available electronically at http:/ /gltrs.grc.nasa.gov 


\title{
Hall Thruster Technology for NASA Science Missions
}

\author{
David Manzella \\ National Aeronautics and Space Administration \\ Glenn Research Center \\ Cleveland, Ohio 44135 \\ David Oh \\ Jet Propulsion Laboratory \\ California Institute of Technology \\ Pasadena, California 91109 \\ Randall Aadland \\ Aerojet Corporation \\ Redmond, Washington 98052
}

The performance of a prototype Hall thruster designed for Discovery-class NASA science mission applications was evaluated at input powers ranging from 0.2 to 2.9 kilowatts. These data were used to construct a throttle profile for a projected Hall thruster system based on this prototype thruster. The suitability of such a Hall thruster system to perform robotic exploration missions was evaluated through the analysis of a near Earth asteroid sample return mission. This analysis demonstrated that a propulsion system based on the prototype Hall thruster offers mission benefits compared to a propulsion system based on an existing ion thruster.

\section{Introduction}

One of the major objectives of the National Aeronautics and Space Administration (NASA) is robotic exploration of the solar system to search for evidence of life, to understand the history of the solar system, to search for resources, and to support future human exploration. ${ }^{1}$ The specific missions that are conducted to accomplish these goals are determined primarily based on prioritized recommendations from surveys of recognized scientists and experts in these fields. ${ }^{2}$ However, NASA's ability to accomplish these robotic space science missions is directly determined by the resources provided to the agency to perform these tasks. To reduce the cost of performing these missions or to enable missions that cannot currently be accomplished, NASA invests in the development of advanced technologies that support these science objectives. One particular advanced technology area that NASA invests in for this purpose is space propulsion.

The technology of advanced space propulsion is important to robotic solar system exploration primarily due to the challenges of sending spacecraft to distant destinations. This challenge can be met using two separate propulsion systems: a launch system capable of providing the thrust-to-weight required to achieve Earth orbit and an in-space propulsion system that can subsequently propel a spacecraft to its intended final destination. The technology utilized to launch spacecraft into Earth orbit has changed little over the last forty years. More importantly the cost of space launch has remained nearly constant over that time period at approximately $\$ 10,000$ per kilogram, and is expected to remain at that level for the foreseeable future. ${ }^{3}$ Therefore, NASA's investment in space propulsion has targeted advanced in-space propulsion technologies that can offer dramatic improvements in propellant fuel economy relative to conventional state-of-the-art systems.

These fuel efficient propulsion technologies, collectively referred to as electric propulsion, achieve this propellant saving, often described in terms of thrust per unit of mass flow, or specific impulse, by using electric power, generated on-board the spacecraft typically using a photovoltaic solar array. The benefits provided by high specific impulse can include a significant reduction in the amount of propellant required to reach distant destinations from Earth orbit. This dramatically reduces overall launch mass, thereby enhancing or even enabling robotic solar system exploration missions. The disadvantages of these advanced propulsion technologies include the low levels 
of acceleration they provide, which necessitate operation for thousands of hours to provide the total impulses needed to reach distant destinations, the cost, mass, and complexity of the electric propulsion and power systems, and the reduced solar irradiance available for photovoltaic power generation at the outer reaches of the solar system.

To address these disadvantages electric propulsion systems have been developed that operate efficiently for long periods of time for a range of input powers. High efficiency minimizes the size and expense of the on-board power system. Reliable long-term operation allows continuous use for years to provide the impulse required to reach distant destinations. High throttle-ability permits operation over a range of input powers accommodating changes in available power as a spacecraft leaves Earth orbit traveling away from the Sun. The first such system used for solar system exploration was the ion thruster system developed by the NASA Solar Electric Propulsion Technology Applications Readiness Program (NSTAR). ${ }^{4}$ The Deep Space 1 spacecraft, launched in 1998, was able to image the Braille asteroid during a flyby and to gain scientific data during a rendezvous with the comet Borrelly using the NSTAR propulsion system. ${ }^{5}$ More recently NASA designed the Dawn mission to aid in the understanding of the conditions and processes present in the earliest epoch of the solar system. ${ }^{6}$ This mission, planned for launch in 2006, will also utilize an NSTAR system to orbit asteroids 4 Vesta and 1 Ceres.

NASA continues the development of improved advanced electric propulsion technologies in order to increase their capability to perform missions such as Deep Space 1 and Dawn. These efforts are the responsibility of the InSpace Propulsion Technology Program, as part of NASA's Science Mission Directorate. The primary focus of this program is NASA's Evolutionary Xenon Thruster (NEXT) propulsion system. NEXT is an ion thruster system that improves upon NSTAR by: increasing the maximum operating power from 2.3 kilowatts to 7 kilowatts, increasing throttle-ability from a range of 5:1 to 10:1, increasing the maximum specific impulse from 3200 seconds to over 4000 seconds, and by increasing the thruster total impulse by a factor greater than three. ${ }^{7}$ The NEXT ion propulsion is on track to be readied for operational use as early as the end of $2006^{8}$

In 2004 the In-Space Propulsion Technology Program conducted a study to quantify the potential benefit of using NEXT and NSTAR ion thruster systems and a proposed Hall thruster propulsion system for future robotic solar system exploration missions. ${ }^{9,10}$ This study considered both New Frontiers class science missions, that are cost capped at $\$ 750 \mathrm{M}$, and Discovery class science missions, that are cost capped at $\$ 300 \mathrm{M}$. A Hall thruster propulsion system was considered as part of this technology mission assessment study due to advancements in Hall thruster technology that have occurred during the past several years. These advancements included increases in throttleability, specific impulse, and thruster efficiency ${ }^{11}$ and the successful demonstration of Hall thruster propulsion systems for primary propulsion applications. These demonstrations included the United States National Reconnaissance Office's Science Technology Experiments spacecraft launched in $1998^{12}$ and the European Space Agency's Small Missions for Advanced Research in Technology 1 (SMART-1) Lunar probe launched in 2003. ${ }^{13}$ The proposed Hall thruster system evaluated during this technology mission assessment was a system envisioned to operate at power levels of 0.3 to 2.8 kilowatts while providing specific impulse ranging from 1500 to 2800 seconds. The results of this assessment was that a Hall thruster system with these performance capabilities and the ability to provide total impulses approaching that of ion thruster systems provided substantial cost and performance benefits relative to the other advanced electric propulsion technologies for the Discovery class science missions considered. ${ }^{9}$

As a result of this study, the development of a Hall thruster with these characteristics was initiated as the objective of the In-Space Propulsion Technology Program's High Voltage Hall Accelerator (HIVHAC) development project. This paper describes the interim results of this development project, as conducted by a team consisting of the NASA Glenn Research Center (GRC) and the Aerojet Corporation. This team was selected for this development activity due to the prior improvements in Hall thruster capability achieved by GRC $^{11}$ and the successful Hall thruster system development conducted by Aerojet for Earth orbital applications. ${ }^{14}$ Specific activities reported in this paper include the design and fabrication of a Hall thruster for NASA robotic solar system science mission applications, the experimentally evaluated performance of this Hall thruster, the potential mission benefit provided by a thruster with the measured performance characteristics, and future development plans for the HIVHAC project.

\section{Thruster Design}

A development-model Hall thruster was designed to provide performance resulting in propulsion system mission benefits for NASA Discovery science missions. Mission analysis indicated that a 10:1 throttle range, as demonstrated by NEXT, in combination with efficient operation over the entire operating range would provide such benefits. ${ }^{9}$ A range of thruster input powers from $0.3-2.8$ kilowatts was chosen based on the desire to substantially reduce the 0.5 kilowatt minimum power operating point of the NSTAR thruster (the higher power NEXT thruster has a minimum input power of 0.6 kilowatts). Prior Hall thrusters have been designed for single set-point operation 
as might be used for north south station keeping of a geostationary communication satellite ${ }^{15}$ or with a moderate throttle-ability as might be used for a combination of orbit insertion, station keeping, and de-orbit. ${ }^{16}$ Prior to this investigation the challenge of designing a Hall thruster intended for operation over a wide range of input powers as needed for NASA science missions had not been addressed.

Hall thruster throttle-ability, or the capability to operate over a wide range of input powers, is determined by the extent that discharge current and discharge voltage can be varied during operation. A prior investigation sought to explore the range of discharge voltages over which efficient operation can be achieved. ${ }^{17}$ During this investigation discharge voltages ranging from 300 Volts to 1250 Volts were demonstrated. These discharge voltages corresponded to discharge specific impulses from 1600 to 3700 seconds, however, at discharge voltages above 700 Volts efficiency declined. A subsequent investigation was able to extend efficient operation to discharge voltages as high as 1000 Volts through the use of an optimized magnetic field. ${ }^{18}$ This optimized magnetic circuit configuration consisted of a plasma lens that was claimed to improve thruster performance by magnetically insulating the plasma from the channel walls, increasing ionization efficiency, and reducing ion beam divergence. Unfortunately these data were taken at an anode mass flow rate corresponding to a propellant density only $33 \%$ of that used by state-of-the-art Hall thrusters. The initial investigation into high voltage operation, that did consider state-of-the-art propellant densities, concluded that the maximum discharge voltage at which efficient thruster operation occurs decreases with increasing propellant density. ${ }^{17}$ The development-model Hall thruster evaluated during this investigation was designed to operate at state-of-the-art propellant densities at discharge voltages ranging from 300 Volts, as employed by Hall thrusters used for Earth orbital applications, to a high of 800 Volts. An optimized magnetic field configuration utilizing a plasma lens as previously demonstrated was utilized to maximize thruster efficiency at elevated discharge voltages, however this range of operating voltages provided a throttle range of less than $3: 1$.

In order to provide the 10:1 throttle range desired to achieve input powers ranging from $0.3-2.8$ kilowatts it was therefore necessary to design the Hall thruster for operation at discharge currents ranging from 1 - 3.5 Amperes. Hall thruster discharge current is determined by anode mass flow rate; however, the ability to operate at a particular discharge current is dependent on the ability of the thruster's hollow cathode to provide an emission current equivalent to that discharge current. The cathode technology chosen for this application was a xenon-fueled hollow cathode of the type used extensively by ion thrusters, including NSTAR and NEXT. This technology, developed to an advanced level of maturity for charge control of the International Space Station, ${ }^{19}$ has demonstrated operational lifetimes on the order of 30,000 hours in both a stand-alone configuration ${ }^{20}$ and as part of an NSTAR ion engine. ${ }^{21}$ The design of a hollow cathode that is able to provide this type of performance requires a geometry based on several critical dimension that can maintain cathode temperatures in a range consistent with long life. ${ }^{22}$ The necessity of maintaining these critical temperatures within this range means there is a limit to the range of emission currents that can be provided for a given geometry. The International Space Station plasma contactor operates over a 4:1 range of currents from 3 to 13 Amperes. ${ }^{19}$ The NSTAR neutralizer cathode operates over a much narrower range of currents, from 2.5 to 3.25 Amperes. ${ }^{21}$ The cathode used for the development model HIVHAC thruster was based on the NSTAR cathode with a modified geometry to accommodate the lower minimum current. ${ }^{23}$

The final challenge with respect to the performance of this Hall thruster was to assure efficient operation. Prior Hall thruster designs have shown a trend of decreasing efficiency with decreasing thruster size, yet thruster size is primarily dictated by the need to maintain a discharge channel sized for the desired anode mass flow rate. ${ }^{24}$ The family of Hall thrusters including the SPT-50, SPT-100, and SPT-140 illustrates this trend ${ }^{25,26,27}$ These thrusters are designed to operate at discharge currents of 1.05 Amperes, 4.5 Amperes, and 15 Amperes respectively. The measured efficiency of each of these thrusters is shown in Table 1. The projected Hall thruster performance shown to offer mission benefits robotic science missions assumed efficiencies from 0.5 to 0.6 at power levels above 1 kilowatt and efficiencies from 0.4 to 0.5 at power levels below 1 kilowatt. In order to achieve these goals it was necessary to improve the efficiency of low current Hall thrusters. This investigation sought to achieve the targeted efficiencies at discharge currents from 1 to 3.5 Amperes by minimizing the power required by the electromagnets, minimizing cathode mass flow rate, and utilizing an optimized magnetic circuit configuration.

Table 1. Efficiency versus thruster size

\begin{tabular}{cccc}
\hline \hline Thruster & Mass flow rate & Discharge Current & Efficiency \\
\hline SPT-50 & $1.3 \mathrm{mg} / \mathrm{s}$ & 1.1 Amperes & 0.32 \\
SPT-100 & $5.0 \mathrm{mg} / \mathrm{s}$ & 4.5 Amperes & 0.50 \\
SPT-140 & $16.5 \mathrm{mg} / \mathrm{s}$ & 15.0 Amperes & 0.56 \\
\hline
\end{tabular}


The mechanical design incorporating these features is pictured in Figure 1. This thruster was designed not only to enable a 10:1 throttle range and to provide efficient operation for input powers ranging from 0.3 to $2.8 \mathrm{~kW}$, it was also designed for low mass and low-cost manufacture. Thruster mass, excluding the hollow cathode and thruster mounting structure, was 2.85 kilograms. Including the hollow cathode and the aluminum mounting structure pictured in Figure 1 the total mass was 3.7 kilograms. An additional 0.3 kilogram mass savings could be achieved through the use of a titanium flighttype mounting structure that was also designed as part of the HIVHAC project, however, the current 3.7 kilogram mass compares favorably with the 8.2 kilogram mass of the 2.6 kilowatt NSTAR thruster and the 12.4 kilogram mass of the 7.2 kilowatt NEXT thruster. The objective of low-cost manufacture was addressed by utilizing an integrated design approach that minimized parts count. Excluding fasteners the prototype Hall thruster utilized thirty-nine discrete parts, more than an order of magnitude fewer parts than employed by either the NSTAR or NEXT ion thrusters. An example of how parts count was minimized include the use of a single coaxial outer electromagnet as opposed to the four individual coils that have been traditionally used in Hall thruster design. Additionally a

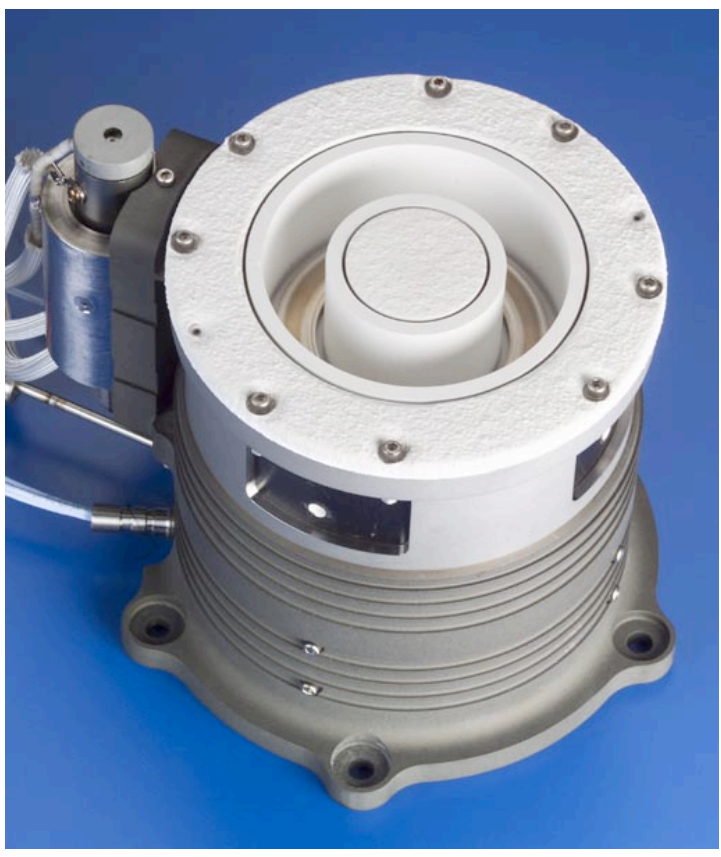

Figure 1. Prototype Hall thruster coaxial cathode mounting arrangement was employed. This approach had been successfully utilized by Aerojet in the design of a flight qualified 4.5 kilowatt Hall thruster ${ }^{14}$ and was successfully demonstrated with a higher power NASA Hall thruster using the same optimized magnetic circuit configuration during a HIVHAC project riskreduction test. While experience gained during the mechanical design of the flight qualified Aerojet 4.5 kilowatt Hall thruster was utilized to ensure a design compatible with typical launch loads, the prototype Hall thruster design was not subject to a comprehensive structural analysis. A steady-state thermal analysis was conducted to investigate the thermal behavior of the prototype Hall thruster design.

\section{Thruster Performance Evaluation}

The performance of the prototype Hall thruster was experimentally evaluated during a series of tests conducted in a 3-meter diameter by 10-meter long cylindrical cryogenically pumped space simulation chamber located at the NASA Glenn Research Center. During this series of tests operational characteristics including anode mass flow rate, cathode mass flow rate, discharge voltage, discharge current, cathode-to-ground voltage, inner magnet voltage, inner magnet current, outer magnet voltage, outer magnet current, and thrust were measured. All these data were taken only after all of these quantities reached their steadysteady state values, however no attempt was made to assure complete thermal equilibrium at each operating point. Data were taken for anode mass flow rates of 1.3, 1.8, 2.2, 3.1, and $3.6 \mathrm{mg} / \mathrm{s}$ and discharge voltages ranging from 200 to 800 Volts in 50 Volt increments. This range of anode mass flow rates provided discharge currents ranging from 1.0 to 3.7 Amperes. These data are shown graphically in Figure 2 and tabulated in the appendix.

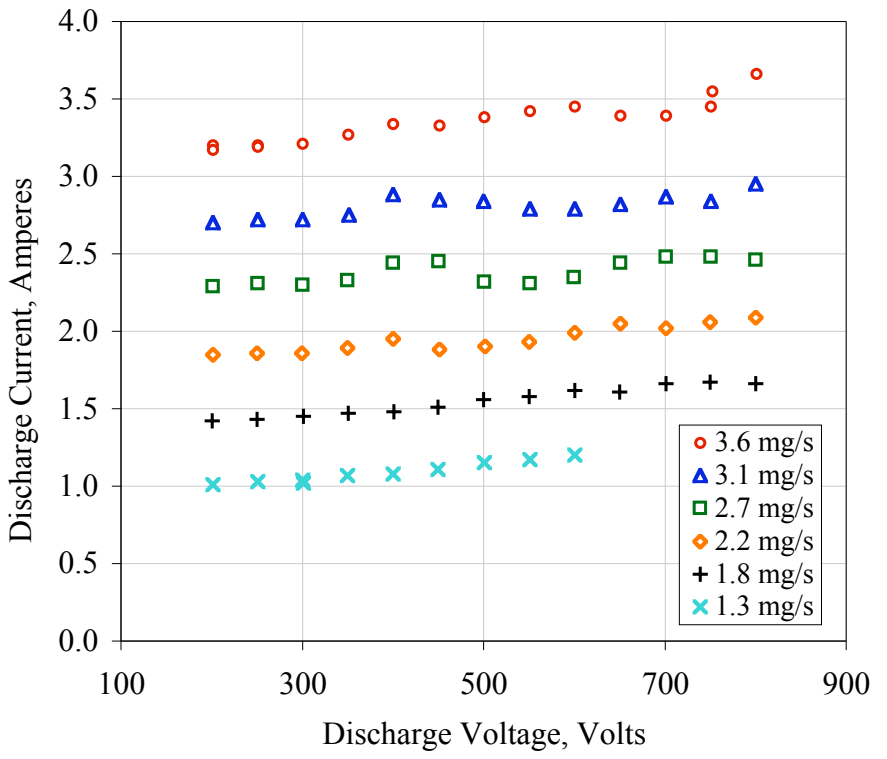

Figure 2. Voltage - current characteristics 
The relationship between discharge current and discharge voltage for each of these anode mass flow rates indicated that this thruster was operating as intended with respect to both propellant utilization and minimization of electron current, characteristics critical for efficient operation. Propellant utilization is an indication of how effectively the thruster ionized and accelerated the propellant provided. A high propellant utilization is important for efficient operation because propellant that was not ionized escapes the thruster discharge channel without being accelerated by the applied discharge voltage, contributing negligibly to thrust. A prior investigation of Hall thruster operational processes indicated that operation with high propellant utilization can be characterized by an ion current equal to the current equivalent of the anode mass flow rate and a ratio of ion current to discharge current of 0.7 or higher. ${ }^{28}$ For all the data measured during this investigation this condition was met. For this condition to be met, the change in discharge current with increasing discharge voltage had to be small. This indicated that the optimized magnetic circuit configuration effectively retarded axial electron transport at elevated discharge voltages. Minimal electron current was previously shown to be essential for efficient operation at high discharge voltages. ${ }^{18}$ These data

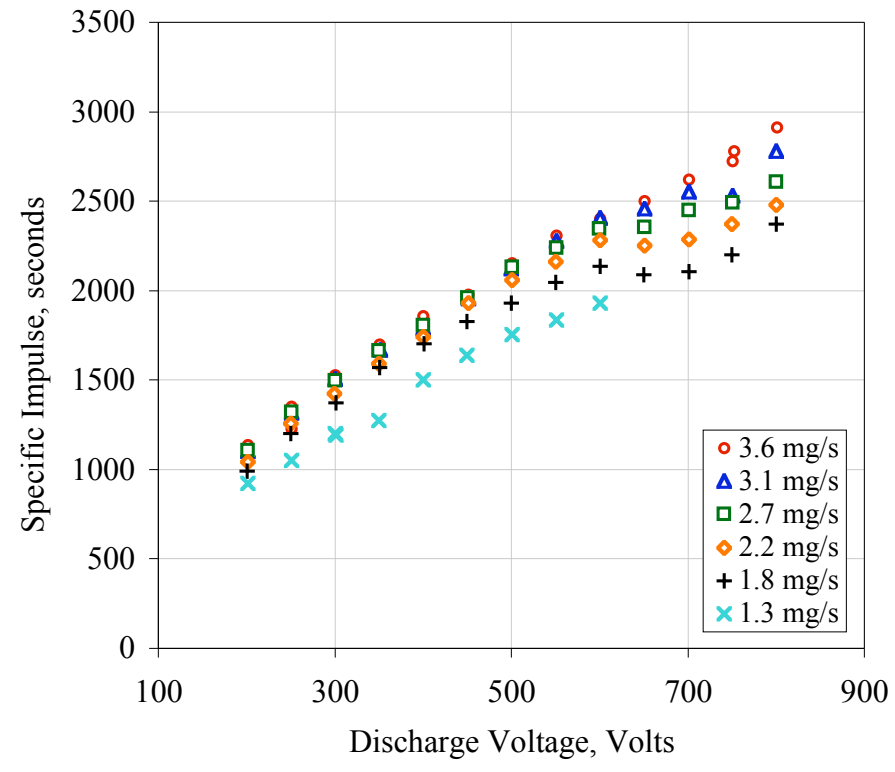

Figure 3. Specific impulse versus discharge voltage

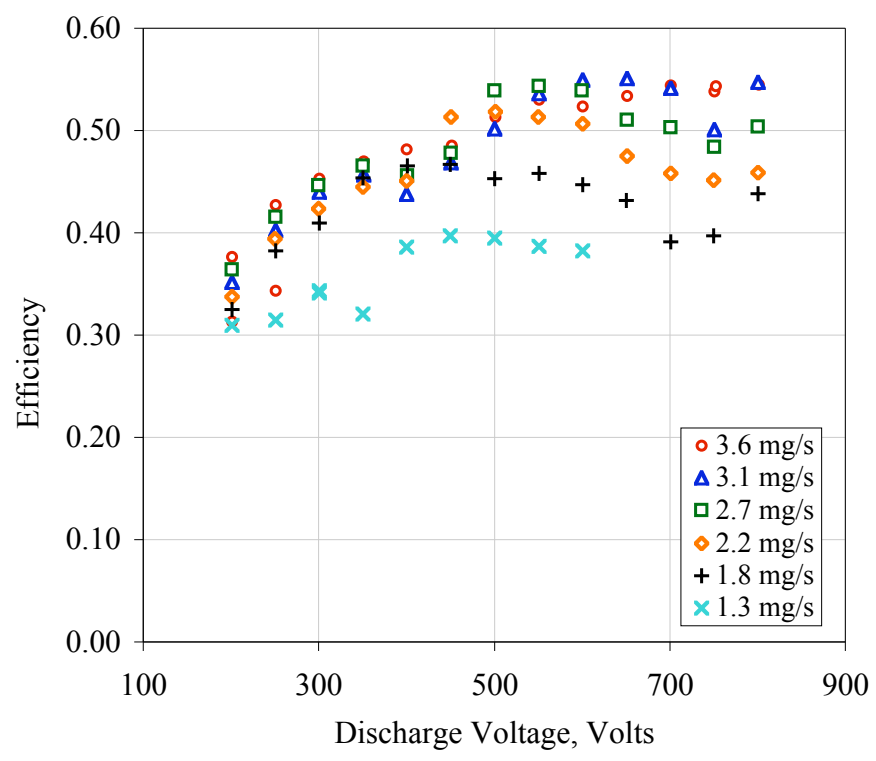

Figure 4.Thruster efficiency versus discharge voltage also indicated that the prototype Hall thruster operated nominally over a wide range of operating characteristics, consistent with the throttle-ability goal. Operation at a maximum power corresponding to discharge current of 3.6 Amperes and a discharge voltage of 800 Volts and a minimum power corresponding to a discharge current of 1 Ampere and a discharge voltage of 200 Volts resulted in a throttle range of 14:1, well in excess of the 10:1 goal.

The performance achieved over this range of operating conditions in terms of specific impulse as a function of discharge voltage is shown in Figure 3 for each of the six different anode mass flow rates that were tested. The spread in specific impulses at each discharge voltage with anode mass flow rate was indicative of a spread in acceleration efficiencies. For example, for a discharge voltage of 500 Volts the average axial ion acceleration voltage for the $1.3 \mathrm{mg} / \mathrm{s}$ anode mass flow rate corresponded to approximately 310 Volts while at $3.6 \mathrm{mg} / \mathrm{s}$ the acceleration voltage was approximately 370 Volts. This suggests that ions were created more readily and further upstream with higher mass flow rates. This was attributed to the higher number densities present at the higher anode mass flow rates. Because ions were formed as a result of atom-electron collisions, increasing the density increased the probability of ionizing collisions. The result was an improvement in specific impulse with anode mass flow rate for a given discharge voltage until a density was reached where essentially all the ions were created upstream of the acceleration region. This typically occurred at state-of-the-art propellant densities, which for this thruster corresponded to anode mass flow rates above $2.7 \mathrm{mg} / \mathrm{s}$. The cathode mass flow rate also had an influence on the spread in specific impulses at each discharge 
voltage for a given anode mass flow rate. At the lowest anode mass flow rates the cathode flow was as much as $18 \%$ of the total flow. At higher anode mass flow rate as little as $7 \%$ of the flow was cathode flow. Since the cathode xenon mass flow did not appreciably contribute to thrust minimizing this flow had a positive impact on both specific impulse and efficiency.

Efficiencies corresponding to the range of operating conditions tested are shown in Figure 4 for each of the six different anode mass flow rates. Peak efficiencies of 0.55 were observed during operation at state-of-the-art propellant densities and discharge voltages of 500 Volts and above. There was a significant decrease in efficiency with decreasing discharge voltage below 500 Volts and efficiency for any discharge voltage generally decreased with decreasing anode mass flow rate. Neither of these observations were unexpected. Efficiency decreased with decreasing anode mass flow rate due to a relatively larger fraction of the input power required to operate the electromagnets and because the cathode mass flow rate was a larger percentage of the total mass flow rate.

\section{Mission Benefit}

The efficacy of a Hall thruster with the performance measured was assessed based on a Discovery-class science mission application. Discovery missions are selected competitively and cover a wide range of scientific goals and destinations. For this study a near Earth asteroid sample return mission with generic destination and launch dates was considered. The mission targeted asteroid Nereus. The mission scenario considered launched to Earth escape with use of the solar electric propulsion system to rendezvous with the asteroid Nereus. The spacecraft then remained in the asteroid's vicinity for 90 days before using the solar electric propulsion system to return to Earth, conduct a flyby, and release the sample for direct re-entry. The basic characteristics of this mission are shown in Table 2.

A separate optimized trajectory is generated for each scenario using the Solar Electric Propulsion Trajectory Optimization Program (SEPTOP), a low thrust optimization tool. All trajectories assumed a nominal array power of

Table 2. Near Earth asteroid sample return mission

\begin{tabular}{lc}
\hline \hline Target Body & Nereus \\
Launch Vehicle & Delta 2925 \\
Power System & $6 \mathrm{~kW}$ solar array at 1 AU \\
Bus Power & 300 Watts \\
Launch Year & $2007 / 08$ \\
Thruster Duty Cycle & $90 \%$ \\
Launch and Rendezvous Dates & Selected by Optimizer \\
Optimization Method & SEPTOP \\
\hline \hline
\end{tabular}

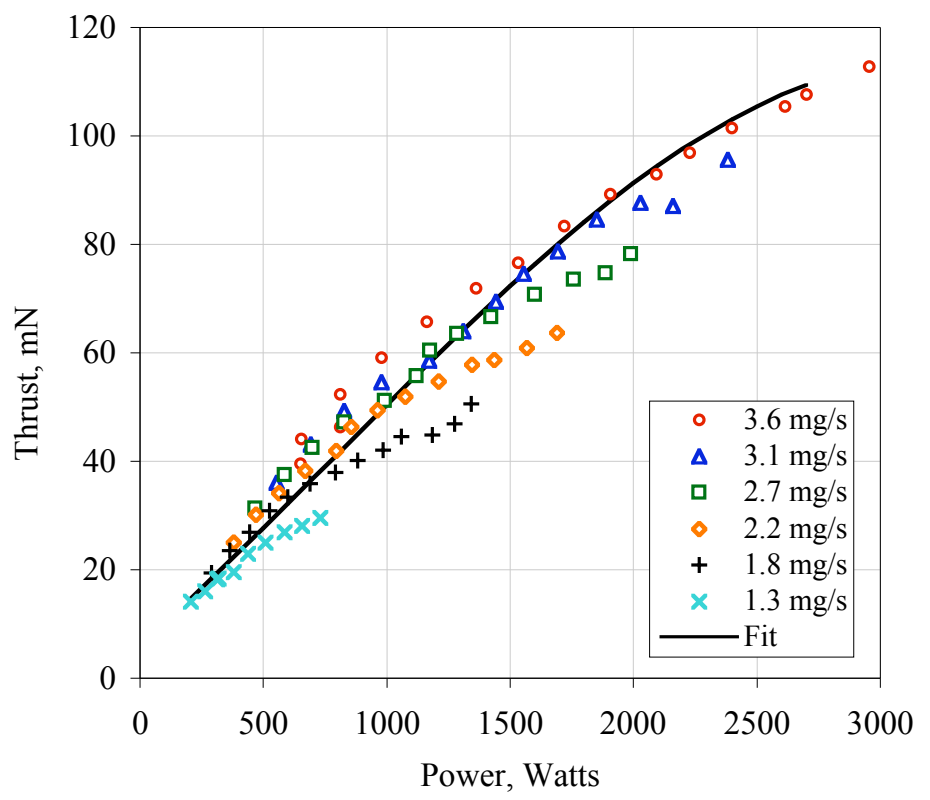

Figure 5. Thrust versus power
6 kilowatts at 1 AU distance from the Sun and included no power margin or allowance for array degradation. The array sizing was typical for a cost capped electric propulsion mission. Power available from the array varied with distance from the sun and was modeled using a high efficiency gallium arsenide array model. The entry velocity at Earth return was not constrained and was optimized for maximum total delivered mass. The entry velocity varied from 13.6 to $14.9 \mathrm{~km} / \mathrm{s}$. By comparison, the entry velocity for the Stardust mission will be approximately $12.6 \mathrm{~km} / \mathrm{s}^{29}$ Higher entry velocities require heavier and more expensive thermal protection systems (TPS). Variations in the mass and cost of the TPS are not accounted for in this analysis.

Hall thruster thrust and mass flow rate were curve fit as a function of input power to create a throttle table. Thrust versus thruster power is shown in Figure 5. The curve was a third order polynomial least squares fit based on a subset of data points corresponding to the highest performance operating condition for each input power. The resultant equation for thrust, in milliNewtons, as a function of thruster input power, in kilowatts, was: 


$$
\text { Thrust }=5.91+41.34 \mathrm{P}+5.75 \mathrm{P}^{2}-2.54 \mathrm{P}^{3}
$$

The mass flow rate versus thruster power was also provided as a third order polynomial least squares fit based on the same data points. This input power also accounted for a $4 \%$ power loss in the power-processing unit. The equation for mass flow rate as a function of input power in kilowatts was:

$$
\text { Mass flow rate }=1.60-0.18 \mathrm{P}+1.30 \mathrm{P}^{2}-0.33 \mathrm{P}^{3}
$$

This curve fit and the experimental data of mass flow rate versus power are shown in Figure 6.

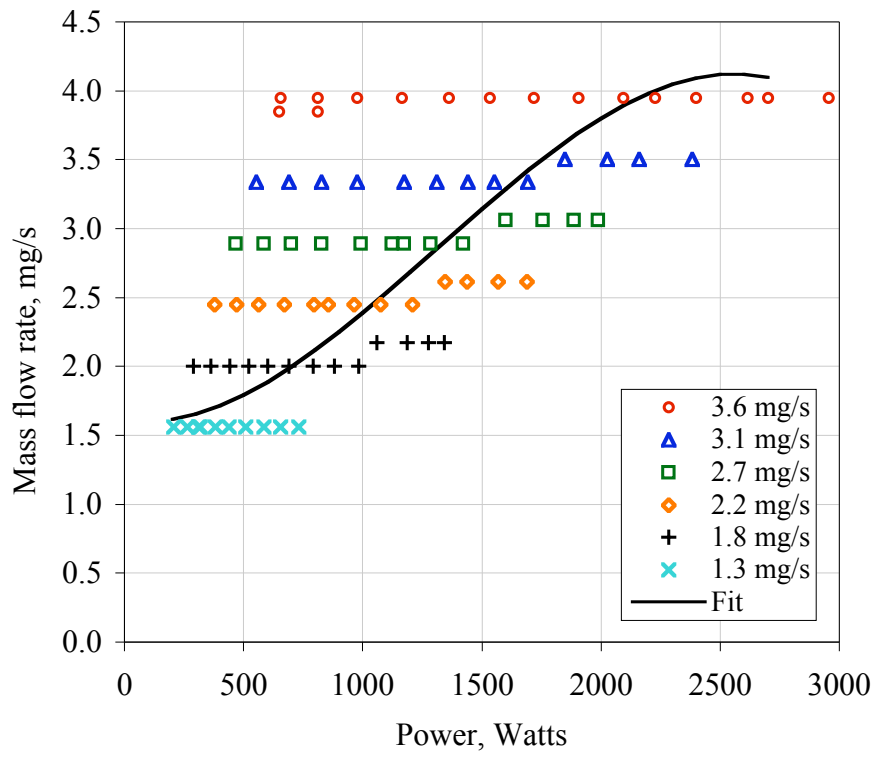

Figure 6. Xenon mass flow rate versus power

The overall mission analysis results for the Near Earth asteroid sample return mission are shown in Table 3. The total mass returned to Earth prior to sample return includes the propulsion system, payload, solar arrays, Earth return vehicle, and main spacecraft bus. Both single and multi-thruster operation was considered. The single and dual NSTAR options both represent state of the art systems. Single NSTAR operation has been flight demonstrated on DS1 and is the baseline for Dawn. Simultaneous operation of multiple thrusters has been flight demonstrated on commercial missions, but has not been demonstrated with the NSTAR thruster. Systems allowing multi-thruster operation are more complex and therefore have higher cost and propulsion system mass than single thruster equivalents. Note that in all cases, an extra thruster and power-processing unit was included on the spacecraft for redundancy. In some cases, an extra thruster was also required to meet xenon throughput requirements.

The results of the analysis indicate that a single Hall thruster can deliver over 70 kilograms more total mass than a single NSTAR thruster for this application. Because the projected Hall thruster system was lighter than the equivalent NSTAR system for this application, the mass available for payload was even greater. Previous work also suggests that the Hall system has the potential to be much less expensive than the NSTAR system for this mission application. ${ }^{9}$ Figure 7 show the spacecraft power versus time history for both the array and the power processing units for the single NSTAR and single Hall scenarios. These profiles look very similar, with both systems operating at roughly equivalent power levels for the same periods of time over the course of the mission. The difference in payload was attributed to the Hall system's higher thrust. This allowed more efficient orbital maneuvers and lower gravity losses enabling the spacecraft to launch with a relatively low $\mathrm{C}_{3}$ and accomplish the rendezvous and return with a smaller $\Delta \mathrm{V}$ than required for the single NSTAR option. The resulting 116-kilogram increase in launch mass more than compensates for the Hall system's 51-kilogram increased propellant usage, ultimately resulting in a $10 \%$ increase in mass returned to Earth.

Table 3. Mission analysis results

\begin{tabular}{ccccc}
\hline \hline Parameter & $\begin{array}{c}\text { 1 NSTAR } \\
\text { thruster }\end{array}$ & 1 Hall thruster & $\begin{array}{c}2 \text { NSTAR } \\
\text { thrusters }\end{array}$ & 2 Hall thrusters \\
\hline Trip Time, & $3.23 \mathrm{years}^{2}$ & $3.15 \mathrm{years}$ & $3.15 \mathrm{years}$ & $3.13 \mathrm{years}$ \\
$\mathrm{C}_{3}$ & $10.2 \mathrm{~km}^{2} / \mathrm{s}^{2}$ & $4.9 \mathrm{~km}^{2} / \mathrm{s}^{2}$ & $2.0 \mathrm{~km}^{2} / \mathrm{s}^{2}$ & $1.9 \mathrm{~km}^{2} / \mathrm{s}^{2}$ \\
Final delivered mass & $664 \mathrm{~kg}$ & $736 \mathrm{~kg}$ & $857 \mathrm{~kg}$ & $851 \mathrm{~kg}$ \\
Launch mass & $996 \mathrm{~kg}$ & $1112 \mathrm{~kg}$ & $1183 \mathrm{~kg}$ & $1186 \mathrm{~kg}$ \\
Drop mass (at Nereus) & $140 \mathrm{~kg}$ & $140 \mathrm{~kg}$ & $140 \mathrm{~kg}$ & $140 \mathrm{~kg}$ \\
Propellant throughput & $191 \mathrm{~kg}$ & $235 \mathrm{~kg}$ & $186 \mathrm{~kg}$ & $195 \mathrm{~kg}$ \\
Free space $\Delta V$ & $6.5 \mathrm{~km} / \mathrm{s}$ & $6.2 \mathrm{~km} / \mathrm{s}$ & $5.2 \mathrm{~km} / \mathrm{s}$ & $4.7 \mathrm{~km} / \mathrm{s}$ \\
Earth entry velocity & $14.9 \mathrm{~km} / \mathrm{s}$ & $14.5 \mathrm{~km} / \mathrm{s}$ & $13.9 \mathrm{~km} / \mathrm{s}$ & $13.6 \mathrm{~km} / \mathrm{s}$ \\
Simultaneous operating thrusters & 1 & 1 & 2 & 2 \\
\hline \hline
\end{tabular}




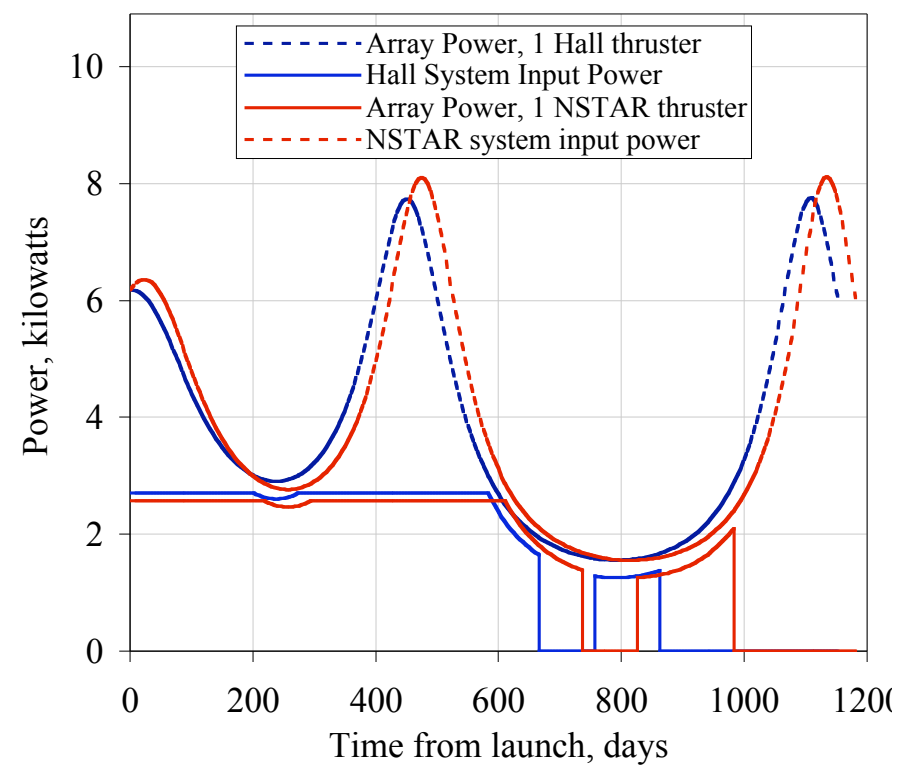

Figure 7. Power versus time, single-operating thruster

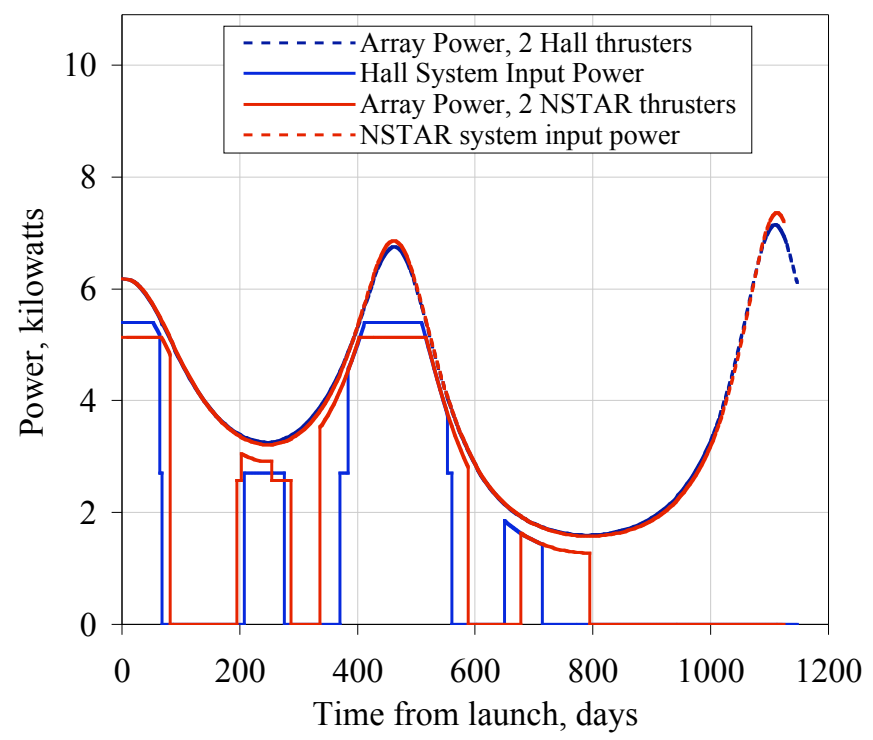

Figure 8. Power versus time, dual-operating thrusters
Figure 8 shows the calculated spacecraft power versus time profiles for dual NSTAR and dual Hall systems. Both systems better utilize the solar array power at launch and at aphelion than the single thruster scenarios. This results in higher thrust levels and better overall performance. Both dual thruster cases launch at very low $\mathrm{C}_{3}$ and accomplish the rendezvous and Earth return while using $20 \%$ less $\Delta \mathrm{V}$ than the single thruster scenarios. The performance difference between the dual Hall and the dual NSTAR cases is relatively small, however, because both systems have sufficient thrust to launch at low $\mathrm{C}_{3}$. As a result, there is only a minimal launch vehicle performance gain to offset the higher propellant utilization of the Hall system. The dual Hall system still performs competitively, however, because its lower gravity losses allow it to accomplish the mission with $10 \%$ less $\Delta \mathrm{V}$ than the dual NSTAR system. These results are consistent with previous findings that, in general, the best mass performance comes from the systems that best utilize available solar array power. ${ }^{9}$ Finally, although the performance of the dual thruster systems were comparable, it should be noted that this same prior investigation concluded that the dual Hall system has the potential to be much less expensive than the dual NSTAR system.

The Hall thruster throttle curve used in this study were based on beginning of life test results and do not account for performance changes that may occur over the life of the thruster. However, such changes are expected to be small. In addition, the results are strongly scenario dependent, and the relative performance of the systems will change as a function of target and launch date. Finally the assumed Hall thruster propellant throughput corresponded to thruster lifetimes in excess of those demonstrated for Earth orbital applications. It was assumed, that through

further development, the thruster lifetime needed for NASA science mission applications can be achieved.

\section{Conclusion}

The ability of using an electric propulsion system based on Hall thruster technology to perform NASA robotic solar system exploration missions was considered. Based on a study of candidate missions it was determined that the propulsion system performance characteristics needed for these applications include efficient operation over a wide throttle range and specific impulses as high as 3000 seconds. A new prototype Hall thruster was designed for these applications since these performance characteristics are substantially different from the characteristics of Hall thrusters developed for Earth orbital applications. This prototype thruster was built and tested for input powers ranging from 0.2 to 2.8 kilowatts. These data were then used to generate a throttle curve used to analyze the mission mass benefit that could be provided for a Discovery-class near Earth asteroid sample return mission relative to the state-of-the-art NSTAR ion thruster system also developed for NASA robotic solar system exploration missions. 
The results of this analysis illustrated that using a Hall thruster propulsion system enables a 70-kilogram increase in delivered spacecraft mass relative to that achievable using the NSTAR ion thruster system.

Developing a Hall thruster system based on the thruster presented here will improve NASA's capability to efficiently and cost effectively perform robotic solar system exploration missions if benefits similar to those identified by this investigation are achievable for a range of exploration missions. Prior to such a development effort there are two considerations that must be addressed. The first is with regard to the thermal performance of the prototype Hall thruster. Although this thruster was designed to operate at propellant densities comparable to those employed by state-of-the-art Hall thrusters, thruster power density was designed to be considerably higher than state-of-the-art thrusters. This was addressed via thermal analysis during the design phase; however, due to resource constraints, tests were not conducted to verify the development thruster's ability to achieve thermal steady-state at the maximum input power. Secondly, the issue of propellant throughput and thruster lifetime must be addressed. The throughputs needed for the Discovery-class missions considered in 2004 by the In-Space Propulsion Technology Program study ${ }^{9}$ corresponded to full power operation for as little as 6,000 hours to as long as 30,000 hours. Current state-of-the-art Hall thruster technology was designed to provide lifetimes of 8,000 hours as required for Earth orbital station-keeping applications. ${ }^{30}$ Prior to a Hall thruster system development for NASA science missions this will have to be further increased. 

Appendix

\begin{tabular}{|c|c|c|c|c|c|c|c|c|}
\hline $\begin{array}{l}\text { Discharg } \\
\text { voltage }\end{array}$ & $\begin{array}{l}\text { Discharge } \\
\text { current }\end{array}$ & $\begin{array}{c}\text { Anode mass } \\
\text { flow rate }\end{array}$ & $\begin{array}{l}\text { cathode mass } \\
\text { flow rate }\end{array}$ & $\begin{array}{c}\text { Magnet } \\
\text { power }\end{array}$ & $\begin{array}{c}\text { Total } \\
\text { power }\end{array}$ & $\begin{array}{l}\text { Thrust } \\
\text { thrust }\end{array}$ & $\begin{array}{l}\text { Specific } \\
\text { impulse }\end{array}$ & Efficiency \\
\hline Volts & Amperes & $\mathrm{mg} / \mathrm{s}$ & $\mathrm{mg} / \mathrm{s}$ & Watts & Watts & $\mathrm{mN}$ & $\mathrm{sec}$ & \\
\hline 201 & 1.01 & 1.33 & 0.23 & 3 & 206 & 14.1 & 922 & 0.31 \\
\hline 251 & 1.03 & 1.33 & 0.23 & 4 & 263 & 16.1 & 1050 & 0.31 \\
\hline 301 & 1.04 & 1.33 & 0.23 & 4 & 317 & 18.4 & 1201 & 0.34 \\
\hline 301 & 1.02 & 1.33 & 0.23 & 4 & 311 & 18.2 & 1192 & 0.34 \\
\hline 350 & 1.07 & 1.33 & 0.23 & 6 & 381 & 19.5 & 1275 & 0.32 \\
\hline 400 & 1.08 & 1.33 & 0.23 & 6 & 438 & 23.0 & 1500 & 0.39 \\
\hline 450 & 1.11 & 1.33 & 0.23 & 8 & 508 & 25.1 & 1639 & 0.40 \\
\hline 501 & 1.15 & 1.33 & 0.23 & 9 & 585 & 26.8 & 1754 & 0.39 \\
\hline 551 & 1.17 & 1.33 & 0.23 & 10 & 655 & 28.1 & 1837 & 0.39 \\
\hline 601 & 1.2 & 1.33 & 0.23 & 11 & 732 & 29.6 & 1932 & 0.38 \\
\hline 201 & 1.42 & 1.78 & 0.23 & 5 & 290 & 19.4 & 989 & 0.33 \\
\hline 251 & 1.43 & 1.78 & 0.23 & 5 & 363 & 23.6 & 1200 & 0.38 \\
\hline 301 & 1.45 & 1.78 & 0.23 & 7 & 443 & 27.0 & 1372 & 0.41 \\
\hline 351 & 1.47 & 1.78 & 0.23 & 8 & 523 & 30.8 & 1569 & 0.45 \\
\hline 401 & 1.48 & 1.78 & 0.23 & 7 & 600 & 33.4 & 1702 & 0.47 \\
\hline 450 & 1.51 & 1.78 & 0.23 & 10 & 690 & 35.9 & 1827 & 0.47 \\
\hline 500 & 1.56 & 1.78 & 0.23 & 13 & 793 & 37.9 & 1930 & 0.45 \\
\hline 551 & 1.58 & 1.78 & 0.23 & 11 & 881 & 40.2 & 2046 & 0.46 \\
\hline 600 & 1.62 & 1.78 & 0.23 & 12 & 984 & 42.0 & 2137 & 0.45 \\
\hline 650 & 1.61 & 1.78 & 0.40 & 11 & 1058 & 44.5 & 2090 & 0.43 \\
\hline 701 & 1.66 & 1.78 & 0.40 & 22 & 1186 & 44.9 & 2106 & 0.39 \\
\hline 750 & 1.67 & 1.78 & 0.40 & 22 & 1274 & 46.9 & 2199 & 0.40 \\
\hline 801 & 1.66 & 1.78 & 0.40 & 14 & 1343 & 50.6 & 2373 & 0.44 \\
\hline 201 & 1.85 & 2.22 & 0.23 & 7 & 379 & 25.0 & 1042 & 0.34 \\
\hline 250 & 1.86 & 2.22 & 0.23 & 6 & 471 & 30.1 & 1255 & 0.39 \\
\hline 300 & 1.86 & 2.22 & 0.23 & 6 & 564 & 34.2 & 1424 & 0.42 \\
\hline 350 & 1.89 & 2.22 & 0.23 & 9 & 670 & 38.2 & 1591 & 0.44 \\
\hline 400 & 1.95 & 2.22 & 0.23 & 13 & 794 & 41.8 & 1743 & 0.45 \\
\hline 451 & 1.88 & 2.22 & 0.23 & 9 & 857 & 46.4 & 1932 & 0.51 \\
\hline 501 & 1.9 & 2.22 & 0.23 & 10 & 963 & 49.4 & 2059 & 0.52 \\
\hline 551 & 1.93 & 2.22 & 0.23 & 12 & 1075 & 52.0 & 2164 & 0.51 \\
\hline 601 & 1.99 & 2.22 & 0.23 & 13 & 1209 & 54.8 & 2281 & 0.51 \\
\hline 651 & 2.05 & 2.22 & 0.40 & 10 & 1345 & 57.8 & 2254 & 0.48 \\
\hline 701 & 2.02 & 2.22 & 0.40 & 21 & 1437 & 58.7 & 2286 & 0.46 \\
\hline 750 & 2.06 & 2.22 & 0.40 & 23 & 1569 & 60.9 & 2373 & 0.45 \\
\hline 801 & 2.09 & 2.22 & 0.40 & 16 & 1689 & 63.6 & 2480 & 0.46 \\
\hline 201 & 2.29 & 2.66 & 0.23 & 7 & 468 & 31.4 & 1107 & 0.36 \\
\hline 251 & 2.31 & 2.66 & 0.23 & 7 & 587 & 37.5 & 1323 & 0.42 \\
\hline 300 & 2.3 & 2.66 & 0.23 & 8 & 699 & 42.5 & 1497 & 0.45 \\
\hline 350 & 2.33 & 2.66 & 0.23 & 10 & 826 & 47.2 & 1662 & 0.47 \\
\hline 401 & 2.44 & 2.66 & 0.23 & 15 & 993 & 51.2 & 1804 & 0.46 \\
\hline 451 & 2.45 & 2.66 & 0.23 & 17 & 1122 & 55.7 & 1962 & 0.48 \\
\hline 501 & 2.32 & 2.66 & 0.23 & 13 & 1174 & 60.5 & 2132 & 0.54 \\
\hline 551 & 2.31 & 2.66 & 0.23 & 11 & 1285 & 63.5 & 2240 & 0.54 \\
\hline 600 & 2.35 & 2.66 & 0.23 & 12 & 1422 & 66.6 & 2346 & 0.54 \\
\hline 651 & 2.44 & 2.66 & 0.40 & 12 & 1601 & 70.7 & 2356 & 0.51 \\
\hline 701 & 2.48 & 2.66 & 0.40 & 18 & 1756 & 73.5 & 2450 & 0.50 \\
\hline 751 & 2.48 & 2.66 & 0.40 & 26 & 1887 & 74.8 & 2490 & 0.48 \\
\hline 800 & 2.46 & 2.66 & 0.40 & 19 & 1988 & 78.3 & 2608 & 0.50 \\
\hline
\end{tabular}




\begin{tabular}{ccccccccc}
\hline $\begin{array}{c}\text { Discharge } \\
\text { voltage }\end{array}$ & $\begin{array}{c}\text { Discharge } \\
\text { current }\end{array}$ & $\begin{array}{c}\text { Anode mass cathode mass } \\
\text { flow rate }\end{array}$ & $\begin{array}{c}\text { Magnet } \\
\text { flow rate }\end{array}$ & $\begin{array}{c}\text { Total } \\
\text { power }\end{array}$ & $\begin{array}{c}\text { Thrust } \\
\text { thrust }\end{array}$ & $\begin{array}{c}\text { Specific } \\
\text { impulse }\end{array}$ & Efficiency \\
\hline Volts & Amperes & $\mathrm{mg} / \mathrm{s}$ & $\mathrm{mg} / \mathrm{s}$ & Watts & Watts & $\mathrm{mN}$ & $\mathrm{sec}$ & \\
\hline 202 & 2.7 & 3.11 & 0.23 & 9 & 553 & 36.0 & 1101 & 0.35 \\
251 & 2.72 & 3.11 & 0.23 & 10 & 691 & 43.1 & 1317 & 0.40 \\
301 & 2.72 & 3.11 & 0.23 & 10 & 827 & 49.3 & 1506 & 0.44 \\
351 & 2.75 & 3.11 & 0.23 & 12 & 978 & 54.6 & 1667 & 0.46 \\
400 & 2.88 & 3.11 & 0.23 & 21 & 1173 & 58.5 & 1788 & 0.44 \\
451 & 2.85 & 3.11 & 0.23 & 26 & 1312 & 64.0 & 1956 & 0.47 \\
500 & 2.84 & 3.11 & 0.23 & 20 & 1441 & 69.4 & 2122 & 0.50 \\
551 & 2.79 & 3.11 & 0.23 & 15 & 1553 & 74.5 & 2277 & 0.54 \\
601 & 2.79 & 3.11 & 0.23 & 17 & 1693 & 78.7 & 2406 & 0.55 \\
651 & 2.82 & 3.11 & 0.40 & 13 & 1849 & 84.5 & 2458 & 0.55 \\
701 & 2.87 & 3.11 & 0.40 & 15 & 2026 & 87.7 & 2550 & 0.54 \\
751 & 2.84 & 3.11 & 0.40 & 28 & 2160 & 87.0 & 2532 & 0.50 \\
801 & 2.95 & 3.11 & 0.40 & 21 & 2383 & 95.6 & 2781 & 0.55 \\
\hline 201 & 3.2 & 3.55 & 0.40 & 11 & 654 & 44.1 & 1139 & 0.38 \\
201 & 3.17 & 3.55 & 0.30 & 12 & 650 & 39.6 & 1049 & 0.31 \\
251 & 3.2 & 3.55 & 0.30 & 9 & 812 & 46.3 & 1226 & 0.34 \\
251 & 3.19 & 3.55 & 0.40 & 11 & 811 & 52.3 & 1351 & 0.43 \\
301 & 3.21 & 3.55 & 0.40 & 13 & 978 & 59.1 & 1526 & 0.45 \\
351 & 3.27 & 3.55 & 0.40 & 15 & 1163 & 65.7 & 1697 & 0.47 \\
401 & 3.34 & 3.55 & 0.40 & 24 & 1362 & 71.9 & 1858 & 0.48 \\
452 & 3.33 & 3.55 & 0.40 & 29 & 1533 & 76.6 & 1979 & 0.49 \\
501 & 3.38 & 3.55 & 0.40 & 25 & 1719 & 83.4 & 2155 & 0.51 \\
551 & 3.42 & 3.55 & 0.40 & 22 & 1906 & 89.3 & 2306 & 0.53 \\
601 & 3.45 & 3.55 & 0.40 & 20 & 2094 & 93.0 & 2402 & 0.52 \\
651 & 3.39 & 3.55 & 0.40 & 20 & 2227 & 96.9 & 2502 & 0.53 \\
701 & 3.39 & 3.55 & 0.40 & 21 & 2397 & 101.5 & 2621 & 0.54 \\
751 & 3.45 & 3.55 & 0.40 & 25 & 2615 & 105.5 & 2723 & 0.54 \\
752 & 3.55 & 3.55 & 0.40 & 30 & 2700 & 107.6 & 2779 & 0.54 \\
801 & 3.66 & 3.55 & 0.40 & 22 & 2955 & 112.7 & 2911 & 0.54 \\
\hline \hline
\end{tabular}




\section{References}

${ }^{1}$ National Research Council, Committee on the Scientific Context for Space Exploration, "Science in NASA's Vision for Space Exploration," National Academies Press, Washington, DC, 2005.

${ }^{2}$ National Research Council, Space Studies Board, "NRC Planetary Decadal Report - New Frontiers in the Solar System: An Integrated Exploration Strategy," National Academies Press, Washington, DC, 2003.

${ }^{3}$ Claybaugh, W., et. al, "Extending Human Presence into the Solar System," The Planetary Society, July 2004.

${ }^{4}$ Sovey, J. S., et. al, "Development of an Ion Thruster and Power Processor for New Millennium's Deep Space 1 Mission," $33^{\text {rd }}$ AIAA Joint Propulsion Conference, AIAA-97-2778, July 1997.

${ }^{5}$ Sovey, J. S., Rawlin, V. K., and Patterson, M. J., "Ion Propulsion Development Projects in U.S.: Space Electric Rocket Test I to Deep Space 1," Journal of Propulsion and Power, Vol. 17, No. 3, May-June 2001, pp. 517-526.

${ }^{6}$ Russel, C. T., et. al, "Dawn: A Journey to the Beginning of the Solar System," DLR International Conference on Asteroids, Comets, and Meteors, July-August 2002.

7 Patterson, M. J., et. al, "NEXT: NASA's Evolutionary Xenon Thruster Development Status," $39^{\text {th }}$ AIAA Joint Propulsion Conference, AIAA-2003-4862, July 2003.

${ }^{8}$ Witzberger, K. E. and Manzella, D. H., "Performance of Solar Electric Powered Deep Space Missions Using Hall Thruster Propulsion," $41^{\text {st }}$ AIAA Joint Propulsion Conference, AIAA-2005-4268, July 2005.

${ }^{9}$ Oh, D. "Evaluation of Solar Electric Propulsion Technologies for Discovery Class Missions," $41^{\text {st }}$ AIAA Joint Propulsion Conference, AIAA-2005-4270,, July 2005.

${ }^{10}$ Witzberger, K. E. ., et. al, "NASA's 2004 In-Space Propulsion Re-focus Studies for New Frontiers Class Missions," $41^{\text {st }}$ AIAA Joint Propulsion Conference, AIAA-2005-4271, July 2005.

11 Jacobson, D. and Manzella, D., Hofer, R., and Peterson, P. "NASA's 2004 Hall Thruster Program," 40 th AIAA Joint Propulsion Conference, AIAA-2004-3600, July 2004.

${ }^{12}$ National Reconnaissance Office, "Space Technology Experiment Satellite Completes Mission," Press Release, June 18, 1999.

${ }^{13}$ Racca, G. D. ., et. al, "SMART-1 Mission Description and Development Status," Planetary and Space Science, Vol. 50, Issues 14-15, December 2002, pp 1323-1337.

${ }^{14}$ De Grys, K. et. al, “4.5 kW Hall Thruster System Qualification Status,” 40 ${ }^{\text {th }}$ AIAA Joint Propulsion Conference, AIAA2004-3603, July 2004.

${ }^{15}$ Randolph, T., et. al, "Integrated Test of an SPT-100 Subsystem," 33 ${ }^{\text {rd }}$ AIAA Joint Propulsion Conference, AIAA-19972915, July 1997.

${ }^{16}$ Oleson, S., "Mission Advantages of Constant Power, Variable Isp Electrostatic Thrusters," $36^{\text {th }}$ AIAA Joint Propulsion Conference, AIAA-2000-3413, July 2000.

${ }^{17}$ Manzella, D., Jacobson, D., and Jankovsky, R., "High Voltage SPT Performance," $37^{\text {th }}$ AIAA Joint Propulsion Conference, AIAA-2001-3774, July 2001.

${ }^{18}$ Hofer, R.R. and Gallimore, A.D., The Role of Magnetic Field Topography in Improving the Performance of High-Voltage Hall Thrusters," $38^{\text {th }}$ AIAA Joint Propulsion Conference, AIAA-2002-4111, July 2002.

${ }^{19}$ Kovaleski, S.D., Patterson, M. J., Soulas, G.C., and Sarver-Verhey, T.R., "A Review of Testing of Hollow Cathodes for the International Space Station Plasma Contactor," $27^{\text {th }}$ International Electric Propulsion Conference, IEPC-01-271, October, 2001.

${ }^{20}$ Sarver-Verhey, T. R., "28,000 Hour Xenon Hollow Cathode Life Test Results," $25^{\text {th }}$ International Electric Propulsion Conference, IEPC-97-168, August, 1997.

${ }^{21}$ Sengupta, A., Brophy, J. R., and Goodfellow, K. D., "Status of the Extended Life Test of the Deep Space 1 Flight Spare Ion Engine after 30,352 Hours of Operation," $39^{\text {th }}$ AIAA Joint Propulsion Conference, AIAA-2003-4558, July 2003.

${ }^{22}$ Patterson, et. al., "Plasma Contactor Technology for Space Station Freedom," $29^{\text {th }}$ AIAA Joint Propulsion Conference, AIAA-93-2228, June 1993.

${ }^{23}$ McEwen, H. et. al., "Development of a Hollow Cathode for the High Voltage Hall Accelerator," 41 ${ }^{\text {st }}$ AIAA Joint Propulsion Conference, AIAA-2005-4235, July 2005.

${ }^{24}$ Manzella, D., Jacobson, D., Peterson, P., and Hofer, R., "Scaling Hall Thrusters to High Power," 52nd JANNAF Propulsion Conference, May, 2004.

${ }^{25}$ Manzella,D, Oleson, S., Sankovic,J., Haag,T., Semenkin, A., and Kim, V., "Evaluation of Low Power Hall Thruster Propulsion," 32 ${ }^{\text {nd }}$ AIAA Joint Propulsion Conference AIAA-96-2736, July, 1996.

${ }^{26}$ Brophy, J. R., Barnett, J. W., Sankovic, J. M., and Barnhart, D. A., "Performance of the Stationary Plasma Thruster: SPT$100, " 28^{\text {th }}$ AIAA Joint Propulsion Conference, AIAA-92-3155, July 1992.

${ }^{27}$ Hargus, W., et. al., "Preliminary Performance Results of the High Performance Hall System SPT-140," 36 ${ }^{\text {th }}$ AIAA Joint Propulsion Conference, AIAA-2000-3250, July 2000.

${ }^{28}$ Kim, V., "Main Physical Features and Processes Determining the Performance of Stationary Plasma Thrusters," Journal of Propulsion and Power, Vol. 14, No. 5, Sept-Oct 1998, pp 736-743.

${ }^{29}$ Mitcheltree, et. al., "Aerodynamics of Stardust Sample Return Capsule," Journal of Spacecraft and Rockets, Vol. 36, No. 3, May-June 1999, pp 429-435.

${ }^{30}$ Day, M., Maslennikov, N., Randolph, T., and Rogers, W., "SPT-100 Subsystem Qualifications Status," 32nd AIAA Joint Propulsion Conference, AIAA-1996-2713, July 1996. 


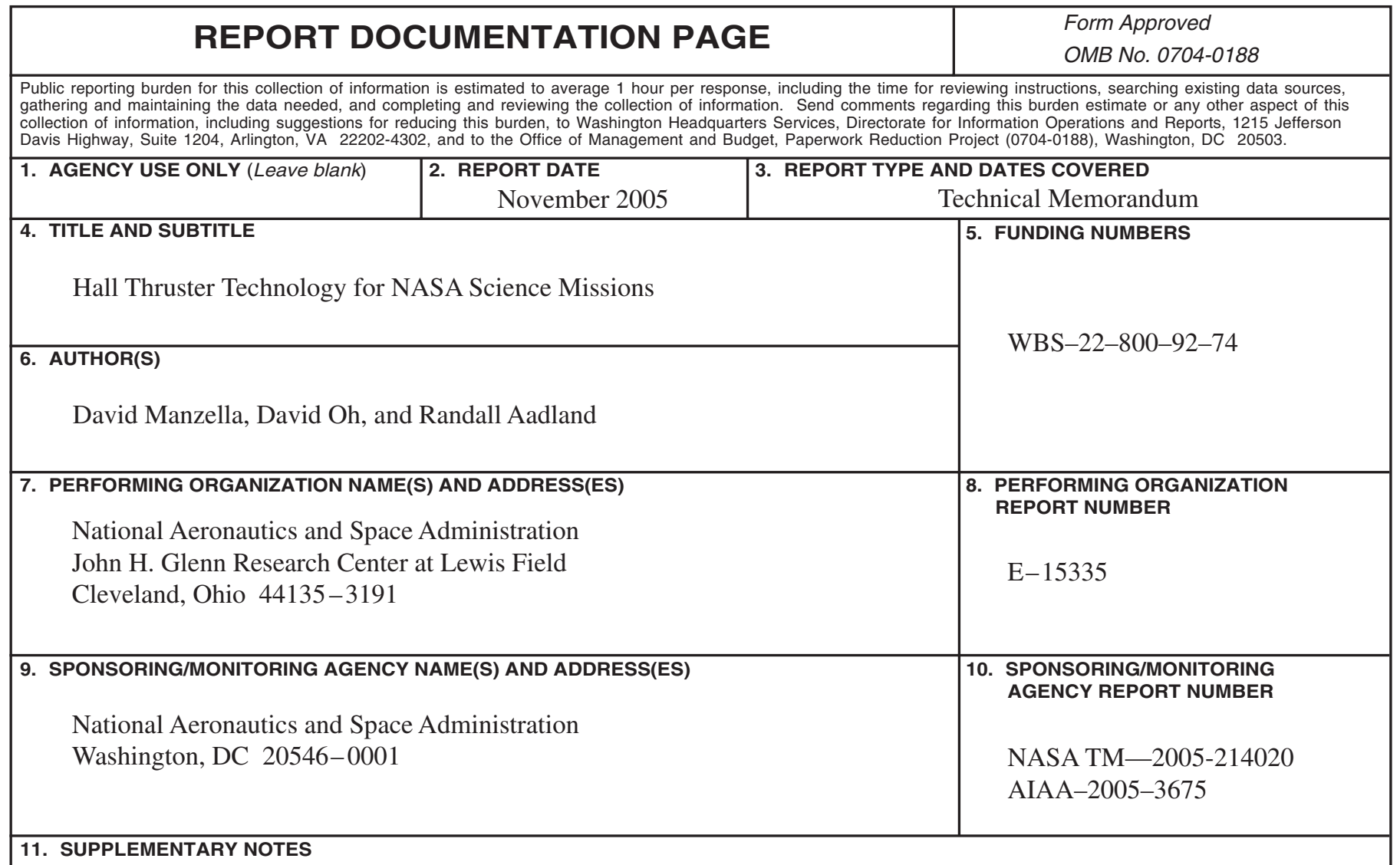

Prepared for the 41st Joint Propulsion Conference and Exhibit cosponsored by AIAA, ASME, SAE, and ASEE, Tucson, Arizona, July 10-13, 2005. David Manzella, NASA Glenn Research Center; David Oh, NASA Jet Propulsion Laboratory; and Randall Aadland, Aerojet Corporation, 11411 139th Place N.E., Redmond, Washington 98052. Responsible person, David Manzella, organization code RPP, 216-977-7432.

\begin{tabular}{|l|l|}
\hline 12a. DISTRIBUTION/AVAILABILITY STATEMENT & 12b. DISTRIBUTION CODE
\end{tabular}

Unclassified - Unlimited

Subject Category: 20

Available electronically at http://gltrs.grc.nasa.gov

This publication is available from the NASA Center for AeroSpace Information, 301-621-0390.

13. ABSTRACT (Maximum 200 words)

The performance of a prototype Hall thruster designed for Discovery-class NASA science mission applications was evaluated at input powers ranging from 0.2 to 2.9 kilowatts. These data were used to construct a throttle profile for a projected Hall thruster system based on this prototype thruster. The suitability of such a Hall thruster system to perform robotic exploration missions was evaluated through the analysis of a near Earth asteroid sample return mission. This analysis demonstrated that a propulsion system based on the prototype Hall thruster offers mission benefits compared to a propulsion system based on an existing ion thruster.

\begin{tabular}{|c|c|c|}
\hline \multicolumn{3}{|l|}{ 14. SUBJECT TERMS } \\
\hline $\begin{array}{l}\text { 17. SECURITY CLASSIFICATION } \\
\text { OF REPORT } \\
\text { Unclassified }\end{array}$ & $\begin{array}{l}\text { 18. SECURITY CLASSIFICATION } \\
\text { OF THIS PAGE } \\
\text { Unclassified }\end{array}$ & $\begin{array}{l}\text { 19. SECURITY CLASSIFICATION } \\
\text { OF ABSTRACT } \\
\text { Unclassified }\end{array}$ \\
\hline
\end{tabular}



